\title{
Distinguishing cirrus cloud presence in autonomous lidar measurements
}

\author{
J. R. Campbell ${ }^{1}$, M. A. Vaughan ${ }^{2}$, M. Oo ${ }^{3}$, R. E. Holz ${ }^{3}$, J. R. Lewis ${ }^{4}$, and E. J. Welton ${ }^{5}$ \\ ${ }^{1}$ Naval Research Laboratory, Monterey, California, USA \\ ${ }^{2}$ NASA Langley Research Center, Hampton, Virginia, USA \\ ${ }^{3}$ Space Sciences and Engineering Center, University of Wisconsin, Madison, Wisconsin, USA \\ ${ }^{4}$ Joint Center for Earth Systems Technology, University of Maryland Baltimore County, Baltimore, Maryland, USA \\ ${ }^{5}$ NASA/Goddard Space Flight Center, Greenbelt, Maryland, USA
}

Correspondence to: J. R. Campbell (james.campbell@ nrlmry.navy.mil)

Received: 12 June 2014 - Published in Atmos. Meas. Tech. Discuss.: 17 July 2014

Revised: 30 October 2014 - Accepted: 15 December 2014 - Published: 27 January 2015

\begin{abstract}
Level-2 Cloud-Aerosol Lidar with Orthogonal Polarization (CALIOP) satellite-based cloud data sets are investigated for thresholds that distinguish the presence of cirrus clouds in autonomous lidar measurements, based on temperatures, heights, optical depth and phase. A thermal threshold, proposed by Sassen and Campbell (2001) for cloud top temperature $T_{\text {top }} \leq-37^{\circ} \mathrm{C}$, is evaluated versus CALIOP algorithms that identify ice-phase cloud layers using polarized backscatter measurements. Derived global mean cloud top heights (11.15 vs. $10.07 \mathrm{~km}$ above mean sea level; a.m.s.l.), base heights (8.76 km a.m.s.l. vs. $7.95 \mathrm{~km}$ a.m.s.l.), temperatures $\left(-58.48^{\circ} \mathrm{C}\right.$ vs. $-52.18^{\circ} \mathrm{C}$ and $-42.40^{\circ} \mathrm{C}$ vs. $-38.13^{\circ} \mathrm{C}$, respectively, for tops and bases) and optical depths (1.18 vs. 1.23) reflect the sensitivity to this constraint. Over $99 \%$ of all $T_{\text {top }} \leq-37^{\circ} \mathrm{C}$ clouds are classified as ice by CALIOP Level-2 algorithms. Over $81 \%$ of all ice clouds correspond with $T_{\text {top }} \leq-37^{\circ} \mathrm{C}$. For instruments lacking polarized measurements, and thus practical estimates of phase, $T_{\text {top }} \leq-37^{\circ} \mathrm{C}$ provides sufficient justification for distinguishing cirrus, as opposed to the risks of glaciated liquid-water cloud contamination occurring in a given sample from clouds identified at relatively "warm" $\left(T_{\text {top }}>-37^{\circ} \mathrm{C}\right)$ temperatures. Although accounting for uncertainties in temperatures collocated with lidar data (i.e., model reanalyses/sondes) may justifiably relax the threshold to include warmer cases, the ambiguity of "warm" ice clouds cannot be fully reconciled with available measurements, conspicuously including phase. Cloud top heights and optical depths are investigated, and global distributions
\end{abstract}

and frequencies derived, as functions of CALIOP-retrieved phase. These data provide little additional information, compared with temperature alone, and may exacerbate classification uncertainties overall.

\section{Motivation}

Cirrus clouds are recognized by sky gazers for their translucent and fibrous appearance, cast frequently as delicate white filaments across otherwise clear blue skies at relatively high tropospheric altitudes. To climate scientists however, cirrus clouds, which are composed almost exclusively of ice crystals, are distinct for their physical and radiative properties (e.g., Liou, 1986). As cold and optically thin counterparts to most liquid-water and mixed-phase clouds (e.g., Sassen and Cho, 1992), the net column-integrated radiative impact of cirrus cloud presence during sunlit hours varies between positive and negative, depending on the relative magnitudes of their simultaneous and offsetting contributions diurnally to tropospheric warming (infrared absorption and reemission) and cooling (solar albedo effects; Stephens et al., 1990). This attribute makes cirrus relatively unique among cloud genera. Combined with their relatively high occurrence frequencies globally (e.g., Holz et al., 2008), cirrus are significant and distinct contributors to climate overall (Sassen, 2002).

Lidars are primary remote-sensing tools used for monitoring cirrus clouds (e.g., Sassen, 1991). Two complementary NASA lidar projects are presently tasked with compiling 
measurements for evaluating global cirrus cloud physical and thermodynamic properties. The NASA Cloud-Aerosol Lidar and Infrared Pathfinder Satellite Observations (CALIPSO) satellite mission features the Cloud-Aerosol Lidar with Orthogonal Polarization (CALIOP ${ }^{1}$; Winker et al., 2010), a two-wavelength (532 and $1064 \mathrm{~nm}$ ) instrument with linear polarization sensitivity at $532 \mathrm{~nm}$. Similarly, the Micropulse Lidar Network (MPLNET ${ }^{2}$; Welton et al., 2002) is well into its second decade of federated ground-based observations using single-channel 523/527/532 nm (depending on the version) eye-safe elastic-scattering instruments (Campbell et al., 2002).

CALIOP and MPLNET measurements are collected autonomously, thus lacking a corresponding scene observer (e.g., a trained meteorological technician), in what has become the new normal for compiling large global data sets with emerging turnkey remote-sensing technologies. (This leaves aside, for the purposes of this paper, a separate debate on the representativeness of ground-based all-sky cameras and/or imaging radiometers in orbit relative to a narrow lidar profiling curtain, given the placement of CALIPSO within the NASA "A-Train" constellation.) In contrast, cloud genus, like that of cirrus, is a distinction based traditionally on visual appearance, which complies with definitions established in atlas publications and is subject to the interpretation and skill of corresponding weather observers (Lynch, 2002; Sassen, 2002). For instance, ice-phase composition, translucence (for which optical depth is an effective proxy), temperature and altitude, properties commonly referenced by researchers evaluating cirrus cloud processes (e.g., Fu et al., 1998), are all ignored as explicit components of the morphologically-based definitions for cirrus clouds (e.g., texture, color, the presence of optical phenomena) maintained by the World Meteorological Organization (WMO, 1975; Lynch, 2002). Each of these causal attributes is considered a relevant element of the WMO definitions, however, which underscores the relatively fine line between physical cloud attributes and their visual interpretation from ground level.

The remote-sensing community has now entered an age where digital cloud characteristics attributable to specific cloud genera are necessary for distinguishing them if we are to maintain the traditional paradigm that inventories cloud presence based on phenomenological characteristics. That is, attributes distinguishable to a ground observer must be effectively translated into a series of cloud-type-dependent parameters retrievable from or directly measurable by autonomous measurements. Without them, isolating cloud genera for potential process study is susceptible to uncertainty and, perhaps worst of all, confusion. A reading of three recent papers specifically investigating cirrus clouds with CALIOP data sets, for example, finds three very different definitions for cir-

\footnotetext{
${ }^{1}$ http://www-calipso.larc.nasa.gov/

${ }^{2} \mathrm{http}: / / m p l n e t . g s f c . n a s a . g o v /$
}

rus cloud presence (Nazaryan et al., 2008; Virts et al., 2010; Thorsen et al., 2011; note that we do not question the veracity of the conclusions in these papers, or fail to recognize that previous papers served a role in motivating their cloud definitions, but are instead clarifying the depth of the challenge for the reader). The potential consequence and impact of cirrus cloud research conducted through CALIOP, MPLNET and other similar lidar projects, for instance, will depend on a consistent and robust approach to distinguishing cloud presence as interpreted from these autonomously collected data sets.

Ultimately, however, the basis for any reliable digital classification depends on the cloud-dependent information available from these relatively simple profiling instruments (simple in the sense that, as the acronym implies, lidars "detect and range"). Lidar data yield cloud boundary heights, which can be related to temperature, given a model or local radiosonde profile. Some, like CALIOP, are equipped with channels that resolve the polarization properties of particle backscatter, which can provide information on likely cloud phase and thus discriminate ice from liquid water, since the former readily depolarizes incident visible radiation (Sassen, 1991). The overwhelming majority of groundbased lidars operated presently do not, however, including those currently in MPLNET. Others (i.e., Raman and highspectral-resolution lidars; Grund and Eloranta, 1990, Goldsmith et al., 1998) can directly measure cloud optical depth, whereas CALIOP and MPLNET instruments can be used only for estimating this parameter. Such advanced systems are a topic best considered at a future date, however. Therefore, if altitude, temperature, optical depth and phase represent the four most practical and relevant lidar-measured parameters for characterizing cirrus cloud properties and are those most relatable to phenomenological WMO definitions, the first three can be estimated (at worst) using nearly all forms of these instruments. Attributing phase, however, will depend on relative technological complexity.

Still, these four parameters in tandem do not fully relate all of the phenomenological characteristics of cirrus clouds apparent to the ground observer (which is presumably why WMO definitions fail to revert to them directly in practice). Furthermore, it is unclear whether or not a static digital classification system for cirrus can be designed based on these four variables alone and whether or not each of them tangibly contributes any practical information content. Critically, as Lynch (2002) succinctly states, "all cirrus clouds are composed of ice, but not all ice clouds are cirrus". Though the predominant nucleation mechanism responsible for their formation remains in question (e.g., Czizco et al., 2013), it is believed that, with limited exceptions (i.e., convective anvils, though a discussion of other less frequent scenarios is given by Sassen, 2002), cirrus cloud morphology begins with the freezing of submicron haze particles at temperatures below the effective threshold for homogeneous freezing of liquid water near $-37^{\circ} \mathrm{C}$ (Pruppacher and Klett, 1997; note that 
for consistency with discussion relating to the homogeneous freezing of liquid water in the literature, we maintain the use of degrees Celsius throughout the manuscript.). Ice phase alone, if resolvable with a given lidar, does not ensure such a distinction, however. For example, most glaciated liquidwater clouds are surely not cirrus, given fundamentally different crystal habits and ice-water paths (Sun and Shine, 1994). Further, a ground observer is likely to recognize, distinguish and report glaciation and perhaps the surrounding remnants of a supercooled liquid-water parent cloud, such as altocumulus (Wang et al., 2004). A lidar, in contrast, would only resolve relatively warm and diffuse ice-phase fallstreaks embedded among pockets of strongly scattering and signalattenuating liquid-water droplets (e.g., Sassen, 1978). Resolving such caveats operationally within an algorithm is obviously daunting.

The results of one study help bridge the gap between visual classification and digital interpretation. Sassen and Campbell (2001; hereafter SC2001) describe a midlatitude cirrus cloud climatology developed over more than a decade using $\sim 2200 \mathrm{~h}$ of episodic ruby lidar $(694 \mathrm{~nm})$ measurements, where a trained observer specifically characterized the cloud scene at the time of profiling. They conclude that for tropospheric cloud identification "in studies lacking visual cloud observations, a minimum cloud top temperature of $-37^{\circ} \mathrm{C}$ be employed to 'identify' cirrus". This is based on roughly $98 \%$ of their visibly classified cirrus cloud sample corresponding with that metric, and owing to the homogenous ice nucleation threshold that ostensibly precludes supercooled liquid-water layers from contributing significantly to what is visibly perceived as cirrus. Cloud top is the essential reference layer, then, since this is the "height at which nucleation is prevalent". SC2001 acknowledge that glaciated liquid cloud clouds (i.e., heterogenous freezing of liquidwater droplets induced by aerosol particles, such as mineral dusts (DeMott et al., 2009) or even other ice crystals (Campbell and Shiobara, 2008), as well as volcanic residues (e.g., Seifert et al., 2011)) and, more notably, sheared cirrus fallstreaks detached from their parent layer exist at relatively warmer apparent cloud top temperatures. Thus, SC2001 rightly do not rule out the existence of relatively "warm" cirrus (i.e., cloud top temperature, $T_{\text {top }}>-37^{\circ} \mathrm{C}$ ). However, and in spite of available polarization measurements, they conclude that most "warm" ice-phase clouds are not cirrus, given their likely conflicting origin. The catch, however, is that some are.

It is presumably the ambiguity in classifying a "warm" ice-phase cloud genus, combined with potential questions regarding the representativeness of a single study conducted at a single midlatitude site, which has precluded the adoption of the SC2001 threshold universally within the community with respect to autonomous lidar measurements (though some have applied it; e.g., Cadet et al., 2003). SC2001 acknowledge the latter point, declaring that "cirrus clouds are the product of weather processes such that their occurrence and macrophysical properties will vary significantly over the globe." Still, despite the increasing density of ground-based lidar profiling facilities, developing a global campaign for reconciling regional variations in cirrus cloud phenomenological characteristics with lidar measurements (i.e., height, temperatures, optical depth and phase) is clearly impractical (Dowling and Radke, 1990, notwithstanding). The community does, however, have access to the CALIOP near-global record $\left(82^{\circ} \mathrm{S}\right.$ to $82^{\circ} \mathrm{N}$; 2006-current), including Level-2 retrievals for cloud altitude, base and top height temperatures, optical depth and phase. These data can be applied in a somewhat consistent fashion, by considering the variability in cloud physical and thermodynamic properties globally with the hopes of refining a set of practical digital classification metrics.

This paper thus describes such a series of tests using Level-2 CALIOP cloud height, temperature, optical depth and phase parameters to evaluate the potential of a uniform, globally applicable technique for identifying the presence of cirrus clouds in autonomous lidar measurements. Each test is designed to isolate ice-phase cloud attributes regionally and globally, in order to recognize the corresponding and relative significance of these four parameters and identify potential caveats. The goal of this work, therefore, is developing a series of dependent regional and global metrics that best characterize cirrus cloud presence, which can be adapted by researchers working within the classical phenomenological framework to specifically extract cirrus cloud observations from autonomous lidar data sets. Note that although the polarization properties of the CALIOP instrument are a primary consideration, we are particularly mindful of historical data, including those from MPLNET, for which polarization is not an option. That is, what may prove practical in distinguishing cirrus from CALIOP data sets may not ultimately satisfy applications without cloud phase estimates, and thus where only cloud heights, temperature, and/or retrievals for optical depth are available (e.g., Chew et al., 2011; Lewis et al., 2015). Therefore, a unifying digital definition should ideally be designed that is applicable to all lidar technologies.

\section{CALIOP Level-2 cloud data sets}

One year (2012) of CALIOP Version 3.02 Level-2 $5 \mathrm{~km}$ cloud profile product (L2CPro-5 $\mathrm{km}$ ) data is investigated. Clouds reported in each L2_CPro-5 km record have been merged so that vertically adjacent layer fragments resolved at different spatial resolutions $(5,20$ and $80 \mathrm{~km}$; Vaughan et al., 2009) are combined into single layers and to ensure a uniform minimum cloud separation threshold of $0.5 \mathrm{~km}$ consistent with SC2001. In accordance with Liu et al. (2009), a corresponding cloud aerosol discriminator (CAD Score; Liu et al., 2009) layer value between 70 and 100 (i.e., high confidence) was required of each cloud layer before merging. Note that the L2_CPro-5km product does not report bro- 
ken but relatively bright liquid-water clouds occurring below $4 \mathrm{~km}$ (all heights a.m.s.l.). These clouds are resolved from single CALIOP signal profiles at a native $0.333 \mathrm{~km}$ along-track resolution, and are generally unlikely, even in polar regions, to correspond with cirrus cloud presence. The L2_CPro-5km product does, however, include those clouds resolved at coarser resolutions (i.e., 20 and $80 \mathrm{~km}$ ) in low signal-to-noise conditions that are likely relevant to our study (i.e., optically-thin clouds like cirrus and/or secondary layers lying below optically-thick cirrus).

Any generic interpretation of sample counts and relative cloud frequencies described in the narrative for anything but the stated intention of each test applied should be considered with these caveats in mind. Further, the reader must also consider the influence of the nadir-viewing lidar geometry and how signal attenuation through optically thick clouds can limit the vertical extent of CALIOP profiling. Zhang et al. (2010), for instance, describe the synergy necessary between CALIOP and the CloudSat millimeter cloud radar (Stephens et al., 2002), also flown within the A-Train, for profiling mixed-phase liquid-layer-topped stratiform clouds. Though the CALIOP geometry is obviously far more preferable to ground-based zenith-profiling lidar application, with respect to attenuation effects, the data are not immune to some degree of sampling bias. The results below, again, are presented in a mostly relative context, except where specifically denoted.

Temperature profiles from Goddard Model Assimilation Office (GMAO) Goddard Earth Observing System Model Version 5 (GEOS-5) products are included in the L2_CPro$5 \mathrm{~km}$ file, and these data are collocated with reported cloud boundary heights. To suppress polar stratospheric cloud contamination, at latitudes $>160^{\circ} \mid$ clouds with top height temperatures $<200 \mathrm{~K}$ are excluded from this analysis (Campbell and Sassen, 2008). By combining cloud phase estimates derived for each layer reported in the L2_CPro-5km files, cloud phase is determined for the merged clouds from the three available categories reported by the CALIOP phase classification algorithm: ice, liquid water and "unknown" (Hu et al., 2009). In the merged data set, ice-phase clouds correspond with a fractional cloud phase that is $100 \%$ ice. Similarly, liquid-phase clouds are $100 \%$ liquid water. Mixed-phase clouds are defined here as those merged layers where the ice and liquid-phase fractions are both non-zero, but where together they sum to $100 \%$. Unknown phase clouds represent cases where the 'unknown' parameter is anything but $0 \%$.

\section{CALIOP cirrus cloud data set tests and discussion}

\subsection{Thermal thresholds vs. CALIOP Level-2 phase retrievals}

The first test establishes a simple baseline comparison between apparent "bookend" scenarios for interpreting cirrus clouds from CALIOP Level-2 data sets. Here, the SC2001 threshold is compared versus all ice clouds identified with CALIOP phase retrieval algorithms. Therefore, "bookend" is defined in the sense that "warm" ice clouds are either ignored completely or considered in full within each subset. Shown in Table 1 are the total numbers of available cloud layers in the merged 2012 L2_CPro-5km product, including sample sizes and relative fractions for those clouds with $T_{\text {top }} \leq-37^{\circ} \mathrm{C}$ and $T_{\text {top }}>-37^{\circ} \mathrm{C}$ (44.66 and $55.34 \%$, respectively). Additionally, corresponding with each cloud and its identified phase, sizes for each sub-sample are shown for ice, liquid, mixed and unknown clouds, including relative fractions. For each of the two ice subsets ("cold" and "warm"), specific relative fractions are also shown.

Over $81 \%$ of all clouds identified by CALIOP algorithms as ice correspond with $T_{\text {top }} \leq-37^{\circ} \mathrm{C}$. Accordingly, approximately $19 \%$ of the ice-phase sample reflects warmer temperatures. However, nearly $97 \%$ of the $T_{\text {top }} \leq-37^{\circ} \mathrm{C}$ cloud sample are identified as ice phase. If "unknown" cases are ignored, this increases to over $99 \%$ of the sample. Given no other information other than simple elastic lidar backscatter (i.e., no visual cues or polarized measurements), the SC2001 threshold proves remarkably stable for distinguishing ice-phase clouds globally. If the SC2001 analysis is further taken at face value, these clouds are very likely all cirrus. SC2001 do not specifically consider or report the probability of "cold" non-cirrus ice clouds present within their sample. Presumably, this scenario occurs, albeit in likely low frequencies, given that glaciation at such temperatures would be dominated by convective processes. Anvils themselves are readily considered cirrus, however. So, it is unclear how any such clouds, if displaced from their convective core, contribute significantly to global inventories.

Figure 1 exhibits these data in a slightly different manner. For all cloud layers considered in Table 1, fractional probabilities are shown for each of the four cloud-phase types in $1^{\circ} \mathrm{C} T_{\text {top }}$ intervals between -60 and $0{ }^{\circ} \mathrm{C}$. Global results are shown, as are those from three latitudinal subsets: $\theta \leq\left|30^{\circ}\right|,\left|30^{\circ}\right|<\theta \leq\left|60^{\circ}\right|$ and $\theta>\left|60^{\circ}\right|$. Superimposed on each plot is the $-37^{\circ} \mathrm{C}$ isotherm. Corresponding sample counts with each case, as a function of phase, are shown in Fig. $2 \mathrm{a}-\mathrm{d}$. At temperatures colder than $-37^{\circ} \mathrm{C}$, ice-phase clouds are dominant according to the CALIOP classification scheme, consistent with Table 1 . The coldest liquid-water clouds are found in nominal amounts beginning at $-39{ }^{\circ} \mathrm{C}$, increasing rapidly for temperatures warmer than $-35^{\circ} \mathrm{C}$ and corresponding with a similarly rapid falloff in ice-phase frequencies. Mixed-phase clouds peak near $-30^{\circ} \mathrm{C}$, and unknown cases maintain generally consistent values between -30 and $0^{\circ} \mathrm{C}$. The global profile is remarkably consistent with those derived regionally.

Shown in Table 2 are corresponding mean cloud base and top heights and temperatures and optical depths, including sample sizes, for all clouds with $T_{\text {top }} \leq-37^{\circ} \mathrm{C}$, all CALIOPidentified ice clouds regardless of $T_{\text {top }}$, and all ice clouds 
Table 1. Total number of cloud layers resolved in the 2012 CALIOP V3.02 L2_CPro-5km product, number of those clouds corresponding with cloud top height temperature $\leq-37^{\circ} \mathrm{C}$, including sub-sample totals and relative, total and ice percentages (as denoted) as function of CALIOP-distinguished cloud phase, and those corresponding with a cloud top height temperature $>-37^{\circ} \mathrm{C}$, again with corresponding itemized cloud phase sample sizes and fractional percentages. Data have been filtered for polar stratospheric cloud occurrence.

\begin{tabular}{|c|c|c|c|c|c|c|c|c|c|}
\hline Available cloud layers & CALIOP phase & $T \leq-37^{\circ} \mathrm{C}$ & Relative \% & Total \% & Ice $\%$ & $T>-37^{\circ} \mathrm{C}$ & Relative \% & Total $\%$ & Ice $\%$ \\
\hline 34216819 & TOTAL & 15327653 & & $44.80 \%$ & & 18889166 & & $55.20 \%$ & \\
\hline CONDITIONS & ICE & 14854198 & $96.91 \%$ & $43.41 \%$ & $81.36 \%$ & 3403873 & $18.02 \%$ & $9.95 \%$ & $18.64 \%$ \\
\hline All $5 \mathrm{~km}$ minimum & LIQUID & 12103 & $0.08 \%$ & $0.04 \%$ & & 11499175 & $60.88 \%$ & $33.61 \%$ & \\
\hline \multirow[t]{2}{*}{$\mathrm{CAD}=70-100$} & MIXED & 118943 & $0.78 \%$ & $0.35 \%$ & & 272248 & $1.44 \%$ & $0.80 \%$ & \\
\hline & UNKNOWN & 342409 & $2.23 \%$ & $1.00 \%$ & & 3713870 & $19.66 \%$ & $10.85 \%$ & \\
\hline
\end{tabular}
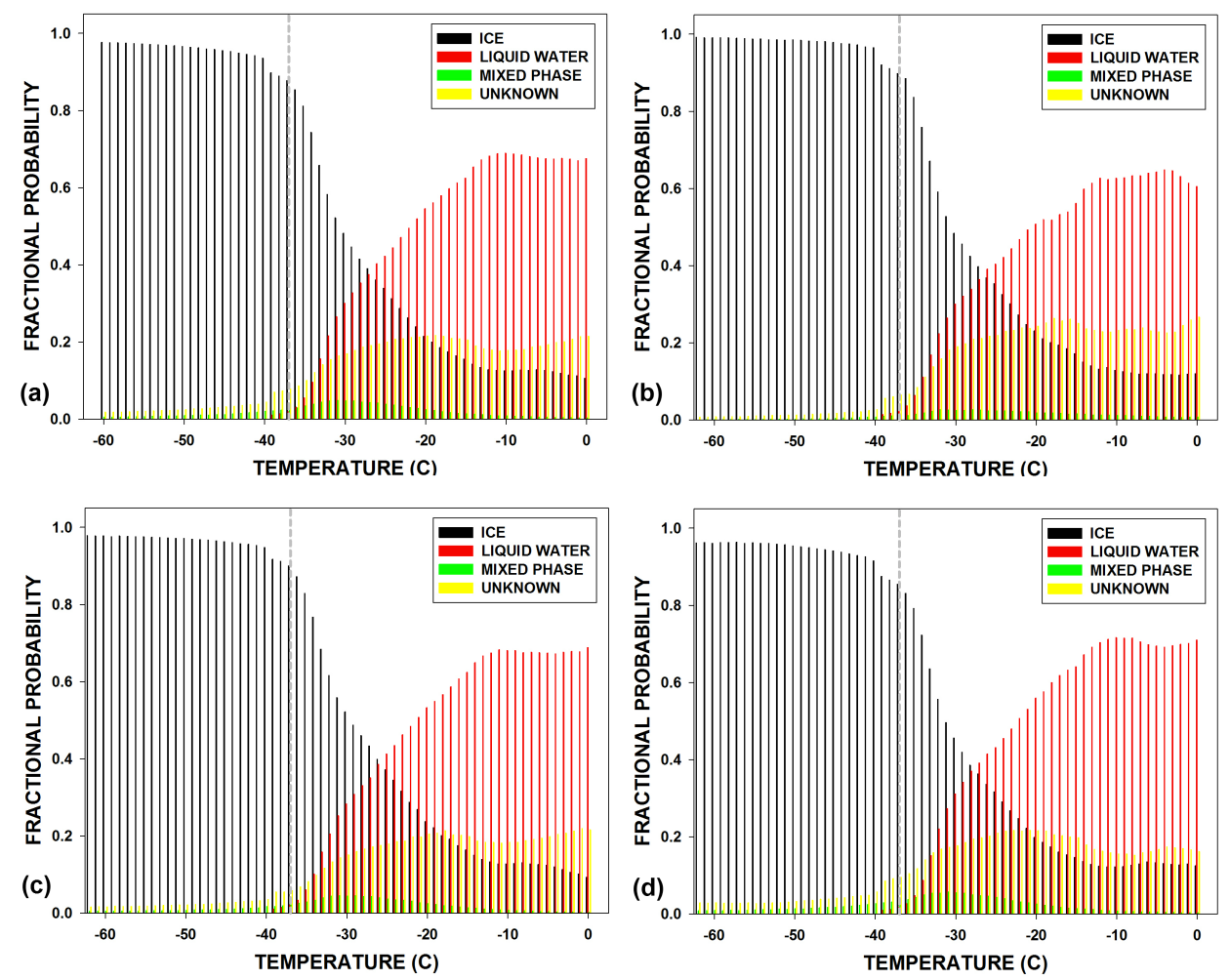

Figure 1. Fractional probabilities at $1{ }^{\circ} \mathrm{C}$ intervals between -60 and $0{ }^{\circ} \mathrm{C}$ for each of the four cloud phase types (see text) identified from the 2012 CALIOP V3.02 L2_CPro-5km, including ice (black), liquid water (red), mixed-phase (green) and unknown (yellow), for (a) the global scale, $(\mathbf{b})$ the tropics $\left(\theta \leq\left|30^{\circ}\right|\right)$, (c) midlatitudes $\left(\left|30^{\circ}\right|<\theta \leq\left|60^{\circ}\right|\right)$ and (d) polar regions $\left(\theta>\left|60^{\circ}\right|\right)$. Superimposed on these data is the $-37^{\circ} \mathrm{C}$ isotherm.

with $T_{\text {top }}>-37^{\circ} \mathrm{C}$. Results are again shown for all clouds, and the three latitudinal subsets. The impact of distinguishing cirrus cloud presence using both bookend scenarios, and thus considering the influence of signal polarization (i.e., phase), is apparent comparing the first two sets of results. Global mean cloud top heights differ by over $1 \mathrm{~km}(11.15$ for ice clouds with top height temperatures $\leq-37^{\circ} \mathrm{C}$ vs. $10.06 \mathrm{~km}$ for all ice clouds). Corresponding temperatures differ by nearly $6.5^{\circ} \mathrm{C}\left(-58.47^{\circ} \mathrm{C}\right.$ vs. $\left.-52.15^{\circ} \mathrm{C}\right)$. Differences are fairly uniform in the midlatitudes and near the poles $\left(\sim 1.1 \mathrm{~km} / 6.5^{\circ} \mathrm{C}\right)$ but less so in the tropics $\left(0.5 \mathrm{~km} / 3.5^{\circ} \mathrm{C}\right)$. Overall, however, these are two very different sets of mean thermodynamic and physical properties, with potentially significant ramifications for global climate models from effects on radiative equilibrium due to a potential parameterization basis (e.g., Stephens et al., 1990).

In Fig. 3, the occurrence frequency of the all-ice cloud subset is shown as a function of cloud top temperature in $1{ }^{\circ} \mathrm{C}$ intervals between -90 and $0{ }^{\circ} \mathrm{C}$, including the global sample (Fig. 3a) and those for each latitudinal band (Fig. 3bd). Superimposed on each image is the $-37^{\circ} \mathrm{C}$ isotherm. A primary mode is evident in the global sample centered near $-55^{\circ} \mathrm{C}$. Secondary modes are evident at -70 and $-80^{\circ} \mathrm{C}$. However, these latter two reflect contribution from the trop- 


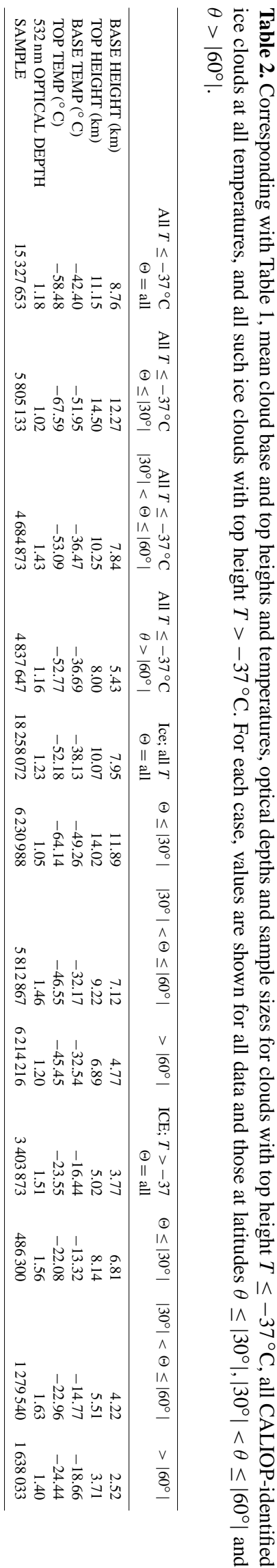

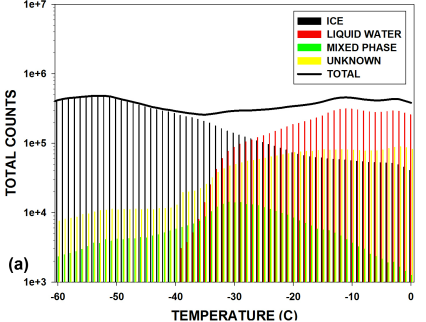
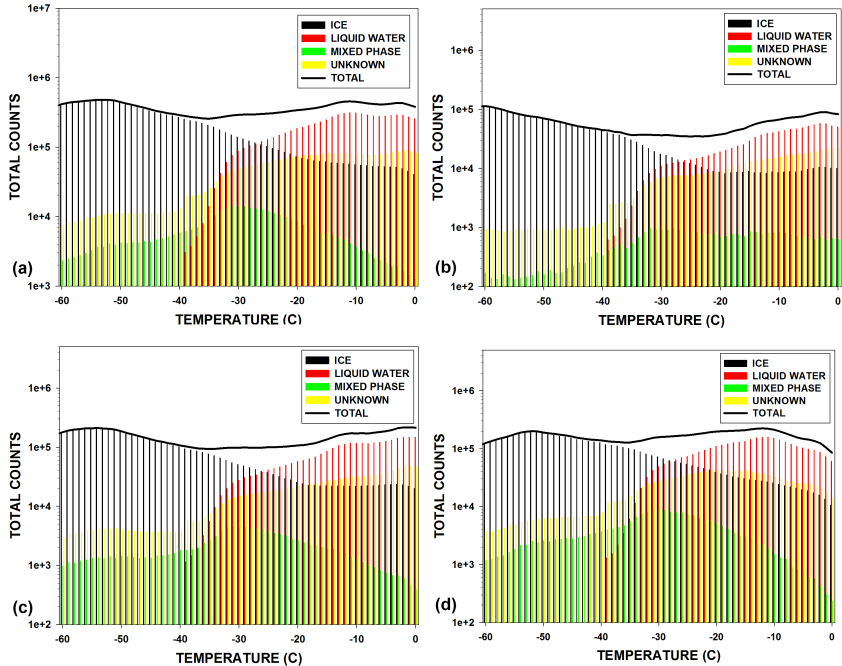

Figure 2. Corresponding with Fig. 1a-d, total counts per $1{ }^{\circ} \mathrm{C}$ interval and for each CALIOP Level-2-retrieved cloud phase and their sum.

ics only (Fig. 3b), and thus likely represent, respectively, mean convective outflow top heights and those corresponding with the tropical tropopause transition layer (Virts and Wallace, 2010; Chew et al., 2012) that are mostly confined to that latitude belt. Sample sizes drop with warming cloud top temperature, beginning at roughly $-50^{\circ} \mathrm{C}\left(-60^{\circ} \mathrm{C}\right.$ in the tropics), but the rate steepens in each sample, beginning near $-35^{\circ} \mathrm{C}$. Interestingly, sample counts warmer than $-37^{\circ} \mathrm{C}$ are much lower in the tropics relative to colder temperatures than those found in the midlatitudes and poles.

As suggested above, roughly $19 \%$ of all ice-phase clouds in this sample exhibit cloud top temperatures warmer than $-37^{\circ} \mathrm{C}$. Further, beginning near $-20^{\circ} \mathrm{C}$ and for increasingly warmer temperatures, sample sizes flatten through $0^{\circ} \mathrm{C}$ (Fig. 3a). Relative ice-phase frequencies similarly flatten for temperatures increasingly warmer than $-15^{\circ} \mathrm{C}$ (Fig. 1), perhaps not-so-coincidentally near the point of maximum offset in saturation vapor pressures between ice and liquid water (e.g., Bergeron-Findeisen effects that favor exclusively non-cirrus ice crystal habits, such as dendrites; Pruppacher and Klett, 1997) and the warmest practical temperatures typically associated with heterogeneous ice nucleation (DeMott et al., 1998, 2010). Less than $6 \%$ of all ice-phase clouds correspond with $T_{\text {top }}>-20^{\circ} \mathrm{C}$ in the global sample. Less than $3 \%$ correspond with $T_{\text {top }}>-10^{\circ} \mathrm{C}$.

Given the reasonable expectation that sample sizes should otherwise decline approaching $0^{\circ} \mathrm{C}$ (e.g., as seen in Fig. 3d), this finding likely signifies the influence of a noise floor in the CALIOP products. Such an artifact will occur for any autonomously-retrieved data product, due to sensor and/or algorithm performance limitations (e.g., the misidentification of optically-thick depolarizing aerosol layers, such as dust, is one example). From Fig. 2, though total cloud counts, includ- 

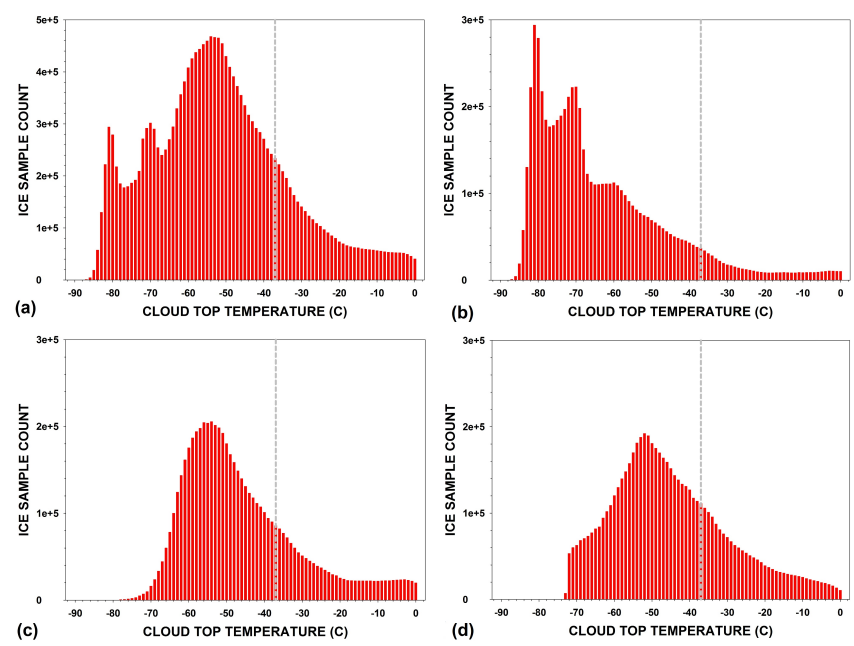

Figure 3. (a) Total global sample counts as a function of top height temperature for all clouds identified as ice phase from 2012 CALIOP V3.02 L2_CPro-5km data set, including overlay of $-37^{\circ} \mathrm{C}$ isotherm, and subset sample counts for (b) the tropics $\left(\theta \leq\left|30^{\circ}\right|\right)$, (c) midlatitudes $\left(\left|30^{\circ}\right|<\theta \leq\left|60^{\circ}\right|\right)$ and (d) polar regions $\left(\theta>\left|60^{\circ}\right|\right)$. The abrupt cutoff at $-73^{\circ} \mathrm{C}$ in (d) is an artifact of the screening process imposed to eliminate polar stratospheric clouds.

ing ice, are relatively low between roughly -40 and $-20^{\circ} \mathrm{C}$, particularly in the tropics, they remain significant overall. Climatological characterizations of cirrus cloud properties derived from data sets that define cirrus simply as being ice clouds (e.g., according to the ice-water phase classification provided by the CALIOP Level-2 data products) are likely biased toward lower mean heights and warmer temperatures and thus do not accurately depict true cirrus cloud properties.

The third set of results in Table 2 relates to those clouds identified as ice but with cloud tops exclusively warmer than $-37^{\circ} \mathrm{C}$, including total and latitudinal mean cloud base and top heights, temperatures and sample sizes. In Fig. 4, cumulative probability densities are shown for the global sub-sample between -37 and $0^{\circ} \mathrm{C}$. Mean global cloud top heights are more than $5 \mathrm{~km}$ lower than the $T_{\text {top }} \leq-37^{\circ} \mathrm{C}$ and all- $T_{\text {top }}$ ice subsets and as much as $35^{\circ} \mathrm{C}$ warmer. By inventorying "warm" ice clouds separately, a distinct set of clouds and corresponding physical properties are depicted in CALIOP data. However, roughly $40 \%$ of these clouds correspond with top heights at $T_{\text {top }} \leq-30^{\circ}$, which is within just a few degrees of the SC2001 threshold. From Fig. 1, and considering that liquid-phase cloud occurrence remains relatively low at temperatures below roughly $-33^{\circ} \mathrm{C}$, many of the clouds right near the threshold potentially represent either "warm" cirrus or sheared fallstreaks. However, any likelihood presumably lessens with each progressively warmer $1{ }^{\circ} \mathrm{C}$ interval. It is effectively impossible to resolve one way or another, at present. However, this "grey area" and the ambiguity that it represents implies that $T_{\text {top }} \leq-37^{\circ} \mathrm{C}$, though

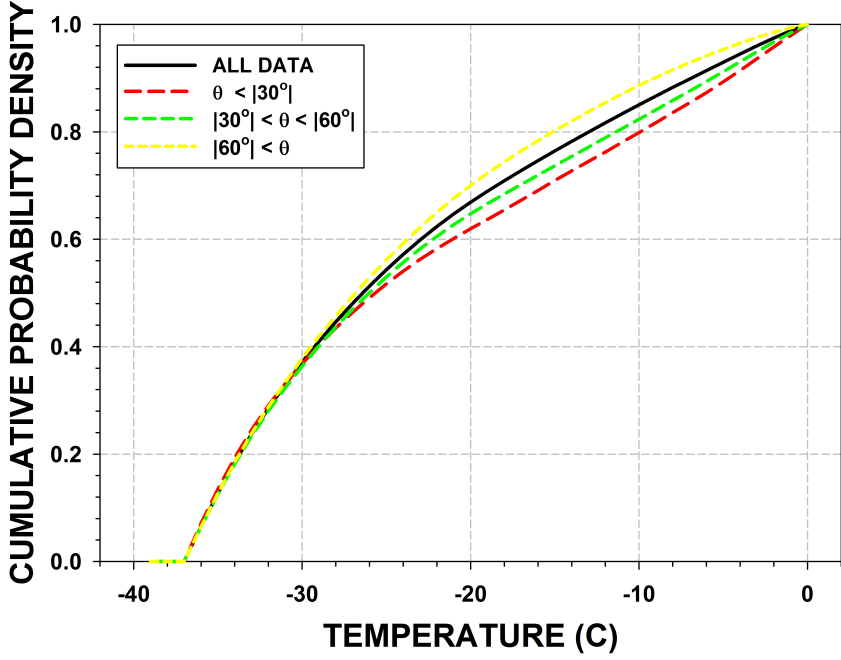

Figure 4. Cumulative probability densities between -37 and $0{ }^{\circ} \mathrm{C}$ for 2012 CALIOP V3.02 L2_CPro-5km clouds identified as ice with top height temperatures $>-37^{\circ} \mathrm{C}$, including all data (black solid) and those subsets for observations found at latitudes $\theta \leq\left|30^{\circ}\right|$ (red dashed), $\left|30^{\circ}\right|<\theta \leq \mid 60^{\circ}$ (green dashed) $\mid$ and $\left|60^{\circ}\right|<\theta$ (yellow dashed).

stable, is likely a conservative threshold, which could presumably be relaxed somewhat with sufficient justification.

In light of this latter point, one potential consideration is the uncertainty of the temperature profiles collocated with lidar-derived cloud boundaries. In deriving Table 2, uncertainties in GMAO-derived temperatures from the upper troposphere are believed to be less than $1^{\circ} \mathrm{C}(\mathrm{M}$. Rienecker, personal communication, 2013). However, if we conservatively apply this standard, relaxing it to $2{ }^{\circ} \mathrm{C}$, and reapply the SC2001 threshold at $-35^{\circ} \mathrm{C}$, thus accounting for potential error, Tables 1 and 2 can be reconsidered. The new results are shown in Tables 3 and 4, respectively. Furthermore, in this new sample, we remove all clouds with $T_{\text {top }} \geq 0{ }^{\circ} \mathrm{C}(55.37 \%$ $T_{\text {top }} \leq-35^{\circ} \mathrm{C}$ vs. $\left.44.63 \%-35^{\circ} \mathrm{C}<T_{\text {top }} \leq 0{ }^{\circ} \mathrm{C}\right)$.

The total ice-phase cloud partitioning fraction for $T_{\text {top }} \leq$ $-35^{\circ} \mathrm{C}$ increases from approximately $81 \%$ to near $84 \%$. Ice-phase clouds make up over $96 \%$ of the full sample, which increases to near $99 \%$ after removing "unknown" cases. Accordingly, mean global cloud top heights are slightly lower, falling from 11.15 to $11.01 \mathrm{~km}$ (over two CALIOP L2_CPro-5km bins at that altitude), and temperatures slightly warmer, rising from -58.48 to $-57.75^{\circ} \mathrm{C}$. Still, the results remain significantly different than that of the corresponding all-ice sample (by offsets of approximately $1 \mathrm{~km}$ and $5.5^{\circ} \mathrm{C}$ at cloud top). Interestingly, the all-ice sample for $T_{\text {top }}>-35^{\circ} \mathrm{C}$ exhibits lower cloud top altitudes of nearly $250 \mathrm{~m}(5.02$ to $4.76 \mathrm{~km})$ and higher temperatures of $2{ }^{\circ} \mathrm{C}\left(-23.55\right.$ to $\left.-21.89^{\circ} \mathrm{C}\right)$, thus reflecting the impact of the original $T_{\text {top }}>-37^{\circ} \mathrm{C}$ sample disproportionality at temperatures just near the threshold (Fig. 3). Adjusting the SC2001 
Table 3. Similar to Table 1; total number of cloud layers resolved in the 2012 CALIOP V3.02 L2_CPro-5km product; number of those clouds corresponding with cloud top height temperature $\leq-35^{\circ} \mathrm{C}$, including sub-sample totals and relative, total and ice percentages (as denoted) as function of CALIOP-distinguished cloud phase, and those corresponding with a cloud top height temperature $\leq 0$ and $>-35^{\circ} \mathrm{C}$, again with corresponding itemized cloud phase sample sizes and fractional percentages. Data have been filtered for polar stratospheric cloud occurrence.

\begin{tabular}{|c|c|c|c|c|c|c|c|c|c|}
\hline Available cloud layers & Caliop phase & $T \leq-35^{\circ} \mathrm{C}$ & Relative \% & Total \% & Ice $\%$ & $0 \geq T>-35^{\circ} \mathrm{C}$ & Relative $\%$ & Total \% & Ice $\%$ \\
\hline 28616072 & TOTAL & 15844609 & & $55.37 \%$ & & 12771463 & & $44.63 \%$ & \\
\hline CONDITIONS & ICE & 15284684 & $96.47 \%$ & $53.41 \%$ & $83.78 \%$ & 2959141 & $23.17 \%$ & $10.34 \%$ & $16.22 \%$ \\
\hline All $5 \mathrm{~km}$ minimum & LIQUID & 34159 & $0.22 \%$ & $0.12 \%$ & & 7105297 & $55.63 \%$ & $24.83 \%$ & \\
\hline \multirow[t]{2}{*}{$\mathrm{CAD}=70-100$} & MIXED & 135266 & $0.85 \%$ & $0.47 \%$ & & 254875 & $2.00 \%$ & $0.89 \%$ & \\
\hline & UNKNOWN & 390500 & $2.46 \%$ & $1.36 \%$ & & 2452150 & $19.20 \%$ & $8.57 \%$ & \\
\hline
\end{tabular}

threshold for uncertainty, as whole, demonstrates stability consistent with applying $-37^{\circ} \mathrm{C}$ alone. Relaxing this value potentially captures more "warm" ice cloud cases, with still only a minor influence of supercooled liquid-water presence (Fig. 1).

\subsection{Constraining cloud phase as a function of cloud top altitude}

In the (increasingly unlikely) event that neither a model nor sounding profile is available for interpolating temperature to lidar-derived cloud boundary heights, the second test is designed to identify the distribution of CALIOPidentified phase frequency globally and regionally versus altitude a.m.s.l. Though this scenario is increasingly redundant, recent studies have used cloud base and top altitudes as screening metrics for distinguishing cirrus cloud presence (e.g., Nazaryan et al., 2008; Thorsen et al., 2011). Considering the direct implication of tropospheric altitude in WMO definitions for cirrus cloud classification, this constraint can become a practical means of ensuring sufficient cloud height and possibly depth, consistent with the likely expectation for cirrus cloud attributes from a corresponding ground observer.

Altitude is ultimately a proxy for temperature, however, and regional variability in that parameter would seemingly limit the application of an altitude metric toward a static global definition for cirrus presence. Global and regional fractional phase probabilities as a function of cloud top altitude, shown in Fig. 5, bear this relationship out. Though icephase clouds are observed at all tropospheric heights globally, except in the tropics, they are increasingly found at lower heights moving poleward. The distribution in the tropics (Fig. 5b) is particularly distinct, though, as liquid-water clouds are dominant up to near $9 \mathrm{~km}$ and ice is not observed below $4 \mathrm{~km}$. Distributions from the midlatitudes and poles are relatively similar, accounting for the shift in increasing ice-phase frequencies to lower heights in the latter, and match the global profile well. This difference in the tropics likely reflects the prevalence of convection in forming clouds, and thus the lofting of liquid water to higher relative nucleation heights in a warmer environment overall.
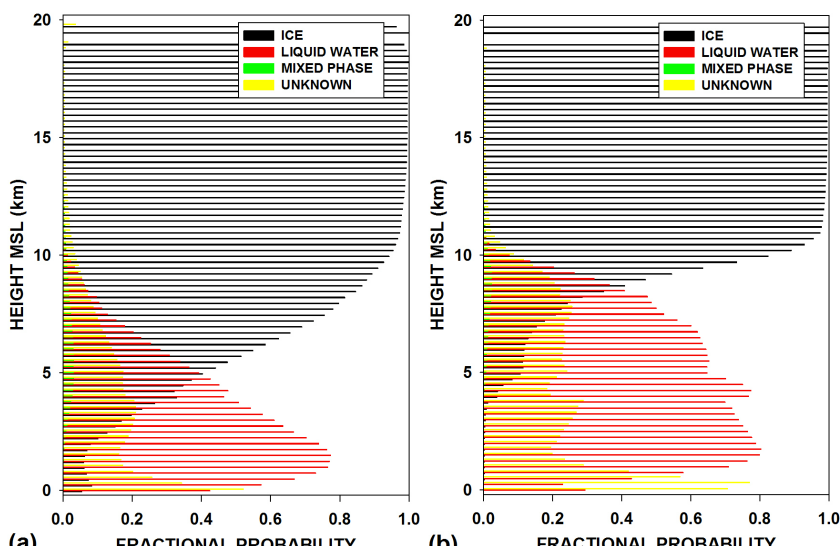

(a)
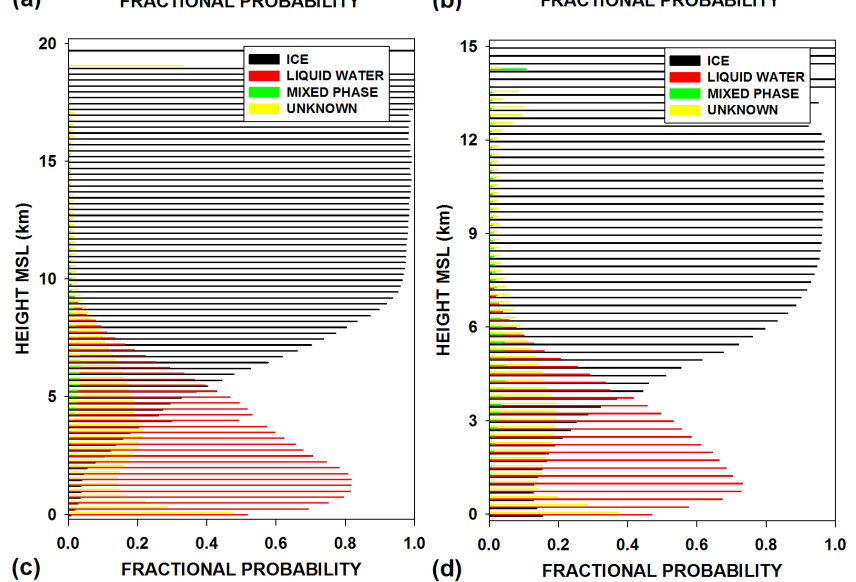

Figure 5. Fractional phase probabilities (ice, liquid water, mixed phase and unknown; see insets) in $250 \mathrm{~m}$ height intervals for 2012 CALIOP V3.02 L2_CPro-5km clouds from 0 to $20 \mathrm{~km}$ a.m.s. 1 for (a) all global cases (ice, liquid water, mixed phase and unknown), (b) the tropics $\left(\theta \leq\left|30^{\circ}\right|\right)$, (c) midlatitudes $\left(\left|30^{\circ}\right|<\theta \leq\left|60^{\circ}\right|\right)$ and (d) from 0 to $15 \mathrm{~km}$ a.m.s.l. at the poles $\left(\theta>\left|60^{\circ}\right|\right)$.

A specific feature of these profiles that may be useful in constraining cirrus identification, particularly when depolarization measurements are not available, is represented by the crossover heights between ice and liquid-phase cloud predominance. Globally, this value is near $5 \mathrm{~km}$. In the tropics, it is near $9 \mathrm{~km}$. In the midlatitudes, it falls just above $5 \mathrm{~km}$ 


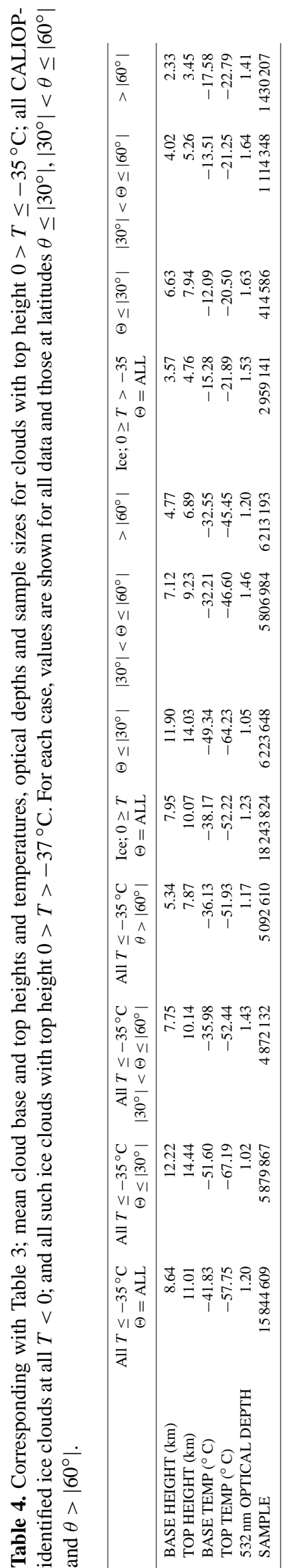

and below $4 \mathrm{~km}$ at the poles. Still, these points represent only very coarse confidence levels and are in fact center points for relatively deep layers where phase ambiguity is highest among the relative distributions. Considering a $20 \%$ probability as a simple qualitative significance threshold, globally there exists a near $3 \mathrm{~km}$ deep layer centered near $5 \mathrm{~km}$ where ice and liquid-water clouds are present in near-similar, and more importantly non-negligible, quantities. The layer is shallower in the tropics and poles, nearer to $2 \mathrm{~km}$ deep, and over $3 \mathrm{~km}$ deep in the midlatitudes. Therefore, depolarization measurements help alleviate confusion regarding phase within what are otherwise ambiguous altitude regimes that vary regionally. Still, they do not help to fully answer the question as to whether or not "warm" clouds are cirrus or glaciated liquid-water clouds in the phenomenological sense. Therefore, while that problem is better constrained, particularly if considered within specific or limited regions, it ultimately remains underdetermined.

\subsection{Constraining cloud phase as a function of cloud optical depth}

As described above, optical depth is a reasonable proxy for estimating cloud translucence. Cirrus clouds that are readily apparent to the ground observer typically correspond with optical depths of between 0 and approximately 3 (Sassen and Cho, 1992), whereas nearly all liquid-water cloud genera exhibit significantly greater values. This suggests that both phase and cirrus cloud identification could potentially be constrained effectively using those cloud optical depths estimated or retrieved directly from autonomous lidar measurements.

Translucence to the ground observer, which for opticallythin clouds like cirrus relates to the measure of blue sky and/or the outline of the solar disk visible through a given cloud layer, does not necessarily translate well into an optical depth collected through an autonomous lidar measurement. In particular, lidar profiles and corresponding opticaldepth retrievals typically reflect processing of measurement averages and/or the integration of retrieval products derived over varying temporal periods. This is the case for CALIOP L2_CPro-5km products investigated here, for instance. Over the course of any integrating period, however, multiple cloud segments or fragments may be sampled, with backscatter then being aggregated into a single instantaneous profile average for processing (Young and Vaughan, 2009; Leahy et al., 2012). If a given cloud layer is temporally persistent and relatively homogeneous, the relationship is consistent. Otherwise, ground-based estimates for translucence and instrument-retrieved optical depth become fundamentally different parameters due to cloud gaps that are inadvertently measured during the sample period.

The third test thus examines whether or not cloud optical depth, as a proxy for translucence, can be applied practically in constraining cirrus or ice cloud presence. Shown in Fig. 6a 
are fractional phase probabilities for all Level-2 CALIOP cloud layers globally as a function of retrieved $532 \mathrm{~nm}$ optical depth. For brevity, only the global composites are shown. In Fig. $6 \mathrm{~b}$ and $\mathrm{c}$, these data are broken down into samples for $T_{\text {top }} \leq-37^{\circ} \mathrm{C}$ and $T_{\text {top }}>-37^{\circ} \mathrm{C}$. Total sample counts corresponding with Fig. 6a-c as a function of optical depth are shown in Fig. 6d-f.

At cloud optical depths below approx. 2.0, over $60 \%$ of the bulk global sample is ice. Consistent with Table 1, for $T_{\text {top }} \leq-37^{\circ} \mathrm{C}$ the sample is almost exclusively ice. Of all counts, $15 \%$ correspond with cloud optical depth $\leq 0.03$, $40 \% \leq 0.30,60 \% \leq 1.00$ and $70 \% \leq 1.40$. At warmer temperatures, the sample is dominated by liquid-water cloud presence, with the greatest ice probability occurring near 0.30 , which corresponds with the approximate threshold for optically-thin cirrus cloud presence derived by Sassen and Cho (1992). The relative fraction for unknown cloud samples increases at the lowest values, reflecting an increased difficulty in making high-confidence phase classifications for very tenuous, weakly scattering layers. (Note that the majority of the optical depth retrievals in this analysis were derived using "unconstrained" retrievals where a priori values for the lidar extinction-to-backscatter ratio and multiple-scattering correction have been applied. These mean values discussed here, therefore, are subject to the uncertainty corresponding with the default value currently applied in Level-2 algorithms (Liu et al., 2009; Vaughan et al., 2009; Young et al., 2013).)

The abrupt changes in the optical-depth distributions that occur at an optical depth of $\sim 2.4$ are the results of an inappropriate choice of cloud lidar ratio. When reliable measurements of clear air can be made immediately above cloud top and below cloud base, estimates of the layer optical depth can be obtained directly from the CALIOP data. In these cases, the optical depths provide a constraint for the lidar equation, and the layer lidar ratios can then be retrieved as part of the solution (Young and Vaughan, 2009). However, for the 2012 CALIOP cloud data, lidar ratios could be obtained this way from only $\sim 2.3 \%$ of all clouds detected. Therefore again, when a measured optical depth constraint is not available, optical depth is estimated using an unconstrained retrieval that requires a priori specification of a type-dependent and layereffective default lidar ratio. This layer-effective lidar ratio is the product of the single-scattering lidar ratio, which depends on the particle phase function and single-scatter albedo, and the effective multiple-scattering factor, which depends on both the lidar-sensing geometry (e.g., field of view and range to target) and the intrinsic and extrinsic properties of the particles being measured.

Version 3 of the CALIOP data processing uses a default lidar ratio of $25 \mathrm{sr}$ for ice clouds and $19 \mathrm{sr}$ for water clouds and a multiple-scattering factor of 0.6 for both cloud types. These default values are chosen to be representative of the distributions of naturally occurring lidar ratios that characterize each type. For optically-thin layers, the CALIOP default values will generate extinction solutions and optical-depth esti- mates with varying degrees of accuracy, depending on how closely the default lidar ratio approximates the actual layer lidar ratio (Young et al., 2013). However, as layers become more optically thick, correct specification of the lidar ratio becomes increasingly important. In particular, an overestimate of the lidar ratio can introduce a numerical instability that will cause the solution process to fail. When this condition is detected within the CALIOP retrieval scheme, the retrieval is halted and then restarted with a reduced value of the lidar ratio (Young and Vaughan, 2009). The sudden discontinuity at $\sim 2.4$ in the optical-depth distributions shown in Fig. 6 thus signifies the appearance of a family of solutions for which the initial lidar ratio had to be reduced by $5 \%$ in order to achieve a physically meaningful solution in an optically thick layer.

Liquid-water clouds require much more frequent lidar ratio reduction than do ice clouds, which may seem paradoxical, since water cloud lidar ratios are much better known and vary much less than ice cloud lidar ratios (for water clouds see $\mathrm{Hu}$ et al., 2006; O'Connor et al., 2004; for ice clouds see Yorks et al., 2011; Sassen and Comstock, 2001). However, CALIOP water cloud multiple-scattering factors are currently not well-characterized, and the default multiplescattering factor of 0.6 may be appropriate only for optically and geometrically thin water clouds. In contrast, Josset et al. (2012) use comparisons with the CALIPSO Imaging Infrared Radiometer to derive a robust empirical estimate of 0.61 for the CALIOP multiple-scattering factor for ice clouds, and this value is applicable across a broad range of optical depths and geometric thicknesses.

In summary, the use of an optical-depth threshold for constraining ice-phase cloud samples, and thus potentially cirrus, exhibits some skill at values below 2.4 in CALIOP data. Thus, consistent with the interpretations of Sassen and Cho (1992), such skill should be transferrable to all autonomous lidar data sets at optical depths less than 3. However, the ambiguity in such an analysis, due to the potential for broken liquid-water cloud layer contamination for integrated sampling averages, can limit its effectiveness and impact. Particularly for "warm" ice clouds, where some refinement would clearly be most useful, and for elastic-scattering instruments that do no measure depolarization, the information content in this parameter remains qualified and thus potentially limited if not applied under careful constraint.

\section{Conclusions}

The complexity in replacing visual ground-observer interpretations of classical cloud genera using autonomous remotesensing measurements, particularly those collected with lidars, will vary with the types of clouds sampled. For cirrus clouds, the results of this study suggest that there will likely never be a single static solution for distinguishing all cirrus clouds (both "cold" and "warm" clouds relative to the 

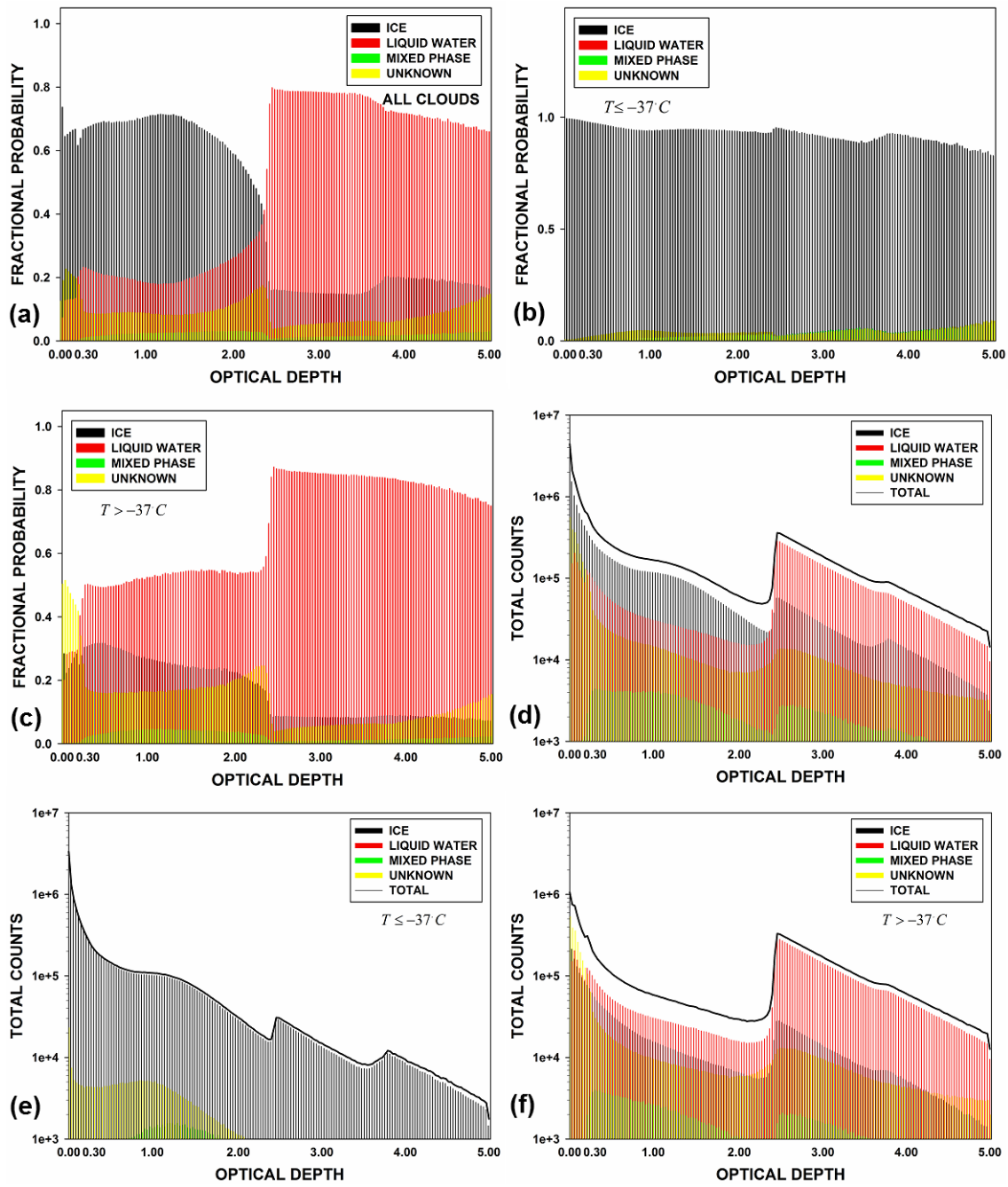

Figure 6. Fractional phase probabilities (ice, liquid water, mixed phase and unknown) in 0.03 cloud optical-depth intervals (532 nm) between 0.00 and 5.00 for 2012 CALIOP V3.02 L2_CPro-5km clouds: (a) for all global cases and temperatures, (b) for all global cases for cloud top temperature $<-37^{\circ} \mathrm{C}$, (c) for all global cases for cloud top temperature $>-37^{\circ} \mathrm{C}$, and (d-f) total counts per cloud phase type in 0.03 optical-depth intervals from the global sample corresponding with (a-c).

threshold temperature for homogenous liquid water freezing) among lidar signal returns, no matter how complex the instrument (i.e., multispectral, polarized) or algorithm. The process involves both assumptions and educated guesswork, and thus some understanding of the physical nature of regional and global cirrus cloud formation and occurrence is essential. In particular, there exists a relatively broad thermal, and spatial, range where relatively warm ice-phase and liquid-water phase clouds are coincident. This ambiguity, exacerbated by some finite likelihood determining whether or not "warm" ice-phase clouds are actually cirrus or some glaciated liquid-cloud remnant (i.e., the heterogenous freezing of liquid-water droplets induced by aerosol particles), cannot be fully reconciled with autonomous measurements alone.
For cirrus, historical research has focused on their specific distinction, given that the physical and radiative properties of upper tropospheric ice-phase clouds differ fundamentally from those of lower-tropospheric glaciated liquidwater clouds. Distinguishing cirrus cloud presence then, and resolving ice cloud inventories relative to their phenomenological and radiative characteristics, has been traditionally approached as a uniquely worthy endeavor. However, considering the breadth of passive and active global satellite remote-sensing observations now available to the community, it has become timely to ask whether or not a cloud paradigm based on traditional phenomenological characteristics remains necessary going forward. For example, given that radiative transfer solutions involving ice rely on parameterizations that vary as a function of crystal habit, and thus effectively cloud top temperature, across the thermal spectrum 
(e.g., Gu et al., 2011), it becomes unclear whether or not the traditional distinction between ice (or any) cloud genera bear any remaining practical significance.

This study was specifically motivated by the goal of evaluating and refining dependent parameters collected and/or associated with autonomous lidar measurements for distinguishing cirrus cloud presence defined based on traditional phenomenological terms. Progress is made by documenting the difficulties surrounding the task and outlining the sensitivity to global and regional cloud properties derived under varying constraints for cirrus presence. It is ultimately hoped, however, that this paper will motivate a discussion within the community that helps resolve lingering questions that would improve such analysis further. Specifically,

1. are climatologies for cold cirrus alone sufficient for characterizing all cirrus physical and radiative properties necessary for conducting representative climate study?

2. conversely, what is the most efficient manner for inventorying ambiguously "warm" ice clouds? Are their physical and radiative characteristics sufficiently unique so as to continue distinguishing their presence separately from traditional cirrus (i.e., do they necessitate their own unique genus)? Do those elements that are actual cirrus (i.e., sheared fallstreaks) exhibit significant occurrence frequencies so as to take further steps in reducing the ambiguity in their identification?

Taking this one step further, however, and reconsidering these questions outside the framework of traditional phenomenological cloud characterization,

1. do the merits of an all-ice climatology or data sample (e.g., using phase alone in a CALIOP-like cloud data set), despite the presence of glaciated liquid-water remnants, make traditional phenomenological definitions obsolete over a significant range of climate study applications?

2. what other factors (i.e., nucleation mechanism through homogeneous vs. heterogenous freezing, supersaturation rates) drive first-order differences in ice cloud macrophysical, microphysical and radiative properties, which ultimately may require resolving in the long run to reach closure on autonomous cirrus cloud identification for climate study?

Upon resolving these questions, the results of this study will either stand on their own merit or can be refined further to make more pragmatic recommendations for the treatment of ice-phase clouds, and cirrus, in future lidar-related studies.

Summarizing then, Sassen and Campbell (2001; SC2001) recommend that, in the absence of any corresponding visual observations (a veritable luxury, considering expanding satellite data availabilities), a thermodynamic threshold of cloud top temperature $T_{\text {top }} \leq-37^{\circ} \mathrm{C}$ be used for identifying cirrus clouds from lidar signal returns. They acknowledge, however, the presence of sheared cirrus fallstreaks and glaciated liquid-water clouds existing at warmer apparent temperatures, though the contribution of supercooled liquid water to cirrus formation is generally considered unlikely. Hence, they also do not rule out the existence of relatively "warm" cirrus (i.e., $T_{\text {top }}>-37^{\circ} \mathrm{C}$ ). This threshold and additional tests involving cloud top heights and optical depths are evaluated primarily as a function of cloud phase using 2012 NASA CALIOP Version 3.01 Level-2 5 km Cloud Profile products. These data have been merged as a function of along-track sampling resolution to combine verticallyadjacent cloud fragments. A cloud separation threshold of $500 \mathrm{~m}$ is also applied to each profile, consistent with SC2001. This study considers lidar-derived cloud altitudes, optical depths and phase determinations, together with independent estimates of temperature obtained from GMAO model data. These parameters were chosen based on their relation to morphological definitions for cirrus cloud classification held currently by the World Meteorological Organization.

The SC2001 threshold proves remarkably effective when applied to the CALIOP data sets. Over $99 \%$ of all corresponding clouds are classified as ice-phase using CALIOP algorithms. Presumably, based on their study, these clouds represent cirrus. Over $81 \%$ of all clouds identified by CALIOP algorithms as ice globally correspond with $T_{\text {top }} \leq-37^{\circ} \mathrm{C}$. These findings reinforce the effectiveness of this threshold in identifying what are strongly believed to be cirrus clouds. The potential for "cold" non-cirrus clouds present in such a sample is unresolved. In particular, for instruments that do not measure signal depolarization, such as the elasticscattering lidars used by the NASA MPLNET, the $-37^{\circ} \mathrm{C}$ $T_{\text {top }}$ threshold temperature represents the only practical metric available for high-confidence identification of ice clouds, and thus presumably cirrus. Reliance solely on CALIOP Level-2 cloud phase distinction generates mean cloud base and top heights and temperatures that, when averaged globally, are $1 \mathrm{~km}$ lower $(11.15 \mathrm{~km}$ vs. $10.07 \mathrm{~km})$ and $6.5^{\circ} \mathrm{C}$ warmer $\left(-58.48^{\circ} \mathrm{C}\right.$ vs. $\left.-52.18^{\circ} \mathrm{C}\right)$ than the SC2001 threshold sample. Less than $6 \%$ of the ice-phase CALIOP sample corresponds with $T_{\text {top }}>-20^{\circ} \mathrm{C}$; this group is very unlikely to represent cirrus clouds and instead likely represents a noise floor in the CALIOP products. Distinguishing the ice phase alone is not sufficient for characterizing cirrus cloud climatological properties in autonomous lidar data sets.

By considering "warm" ice cloud properties separately relative to the SC2001 threshold, a distinct set of cloud top heights and temperatures is derived $\left(5.02 \mathrm{~km}\right.$ and $\left.-23.55^{\circ} \mathrm{C}\right)$ that is over $5 \mathrm{~km}$ lower and $35^{\circ} \mathrm{C}$ warmer than the two bulk sample means, respectively. However, nearly $40 \%$ of the ice-phase sample for $T_{\text {top }}>-37^{\circ} \mathrm{C}$ are colder than $-30^{\circ} \mathrm{C}$, or only a few degrees warmer than that threshold. Considering and accounting for uncertainties in NASA Goddard Model Assimilation Office temperatures, for example, proves 
a sufficient and stable justification for relaxing the threshold slightly (conservatively reapplied here at a threshold of $-35^{\circ} \mathrm{C}$ ), with no apparent loss of fidelity in the mean climatological statistics derived. Liquid-water cloud frequencies derived from CALIOP remain relatively low at temperatures colder than approximately $-33^{\circ} \mathrm{C}$.

It is unclear how to reasonably adjust the thermal threshold any further to account for potentially "warm" cirrus and/or sheared fallstreaks. For lidar data sets that lack phase discrimination, by considering the polarization properties of backscattered signals, the fear of increasing supercooled liquid-water contamination rises with warming temperature. Tests designed for evaluating the potential gain in considering cloud top height and optical-depth information to improve the retrieval identify specific regional tendencies. When compared to the clear delineation between ice and liquid phase samples found near the SC2001 threshold alone, however, its unclear whether these tests provide any additional useful information. If anything, they likely complicate the process and exacerbate the ambiguities of "warm" ice cloud classification. Of specific note, broken liquid-water cloud presence impacts relatively low optical-depth distributions, which limits its practical use as a distinguishing attribute for ice or cirrus.

In closing, the use of polarization-sensitive instruments, and the determination of cloud phase, helps greatly in segregating ice and liquid-phase clouds. However, elasticscattering data sets, like those presently collected by the NASA Micropulse Lidar Network, lack any other viable means for distinguishing cirrus within cloud layer products aside from a thermal threshold (e.g., Lewis et al., 2015). As suggested above, $T_{\text {top }} \leq-37^{\circ} \mathrm{C}$ proves sufficiently robust, if not practically conservative. We further demonstrate that the threshold can be justifiably relaxed through uncertainties in thermal interpolation of model and sounding data to lidar-derived cloud boundary heights. If the community decides, however, that inventorying cirrus alone going forward remains a worthy goal, further attempts to reconcile the nature of "warm" ice-phase clouds using polarization should ultimately prove consistent across all projects such as CALIOP and MPLNET. Thus, it will likely be difficult to avoid thermal constraints like that of SC2001. Otherwise, consistency and fidelity across global climatological data sets are jeopardized. Leaving aside questions raised above regarding the representativeness of ice vs. cirrus cloud inventories, the NASA investment in CALIOP and MPLNET, and the goal for robust cloud climate research overall, justifies some binding reconciliation.

Acknowledgements. This research was conducted through NASA Interagency Agreement NNG13HH10I on behalf of the NASA Micropulse Lidar Network, which itself is supported by the NASA Radiation Sciences Program (H. Maring). Authors M. Oo and R. E. Holz acknowledge support from the Oceanographer of the Navy (N2/N6E) through the Program Office at PEO C4I PMW-120.
Edited by: U. Wandinger

\section{References}

Cadet, B., Goldfarb, L., Faduilhe, D., Baldy, S., Giraud, V., Keckhut, P., and Réchou, A.: A sub-tropical cirrus clouds climatology from Reunion Island (21_S, 55_E) lidar data set, Geophys. Res. Lett., 30, 1130, doi:10.1029/2002GL016342, 2003.

Campbell, J. R. and Sassen, K.: Polar Regions stratospheric clouds at the South Pole from 5 years of continuous lidar data: macrophysical, optical, and thermodynamic properties, J. Geophys. Res., 113, D20204, doi:10.1029/2007JD009680, 2008.

Campbell, J. R. and Shiobara, M.: Glaciation of a mixedphase boundary layer cloud at a coastal Arctic site as depicted in continuous lidar measurements, Polar Sci., 2, doi:10.1016/j.polar.2008.04.004, 2008.

Campbell, J. R., Hlavka, D. L., Welton, E. J., Flynn, C. J., Turner, D. D., Spinhirne, J. D., Scott, V. S., and Hwang, I. H.: Full-time, eye-safe cloud and aerosol lidar observation at Atmospheric Radiation Measurement program sites: Instruments and data processing, J. Atmos. Oceanic. Technol., 32, 439-452, 2002.

Chew, B. N., Campbell, J. R., Reid, J. S., Giles, D. M., Welton, E. J., Salinas, S. V., and Liew, S. C.: Tropical cirrus cloud contamination in sun photometer data, Atmos. Environ., 45, 6724-6731, doi:10.1016/j.atmosenv.2011.08.017, 2011.

Cziczo, D. J., Froyd, K. D., Hoose, C., Jensen, E. J., Diao, M., Zondlo, M. A., Smith, J. B., Twohy, C. H., and Murphy, D. M.: Clarifying the dominant sources and mechanisms of cirrus cloud formation, Science, 340, 1320-1324, doi:10.1126/science.1234145, 2013.

DeMott, P. J., Rogers, D. C., Kreidenweis, S. M., Chen, Y., Twohy, C. H., Baumgardner, D., Heymsfield, A. J., and Chan, K. R.: The role of heterogeneous freezing nucleation in upper tropospheric clouds: inferences from SUCCESS, Geophys. Res. Lett., 25, 1387-1390, 1998.

DeMott, P. J., Sassen, K., Poellot, M. R., Baumgardner, D., Rogers, D. C., Brooks, S. D., Prenni, A. J., and Kreidenweis, S. M.: Correction to "African dust aerosols as atmospheric ice nuclei," Geophys. Res. Lett., 36, L07808, doi:10.1029/2009GL037639, 2009.

DeMott, P. J., Prenni, A. J., Liu, X., Kreidenweis, S. M., Petters, M. D., Twohy, C. H., Richardson, M. S., Eidhammer, T., and Rogers, D. C.: Predicting global atmospheric ice nuclei distributions and their impacts on climate, Proc. Natl. Acad. Sci., 107, 11217-11222, 2010.

Dowling, D. R. and Radke, L. F.: A summary of the physical properties of cirrus clouds, J. Appl. Meteorol., 29, 970-978, 1990.

Fu, Q., Yang, P., and Sun, W. B.: An accurate parameterization of the infrared radiative properties of cirrus clouds for climate models, J. Climate, 11, 2223-2237, 1998.

Goldsmith, J. E. M., Blair, F. H., Bisson, S. E., and Turner, D. D.: Turn-key Raman Lidar for profiling atmospheric water vapor, clouds and aerosols, Appl. Opt., 37, 4979-4990, doi:10.1364/AO.37.004979, 1998.

Grund, C. J. and Eloranta, E. W.: The 27-28 October 1986 FIRE IFO cirrus case study: cloud optical properties determined by high spectral resolution lidar, 
Mon. Weather Rev., 118, 2344-2355, doi:10.1175/15200493(1990)118<2344:TOFICC>2.0.CO;2, 1990.

Gu, Y., Liou, K. N., Ou, S. C., and Fovell, R.: Cirrus cloud simulations using WRF with improved radiative parameterization and increased vertical resolution, J. Geophys. Res., 116, D06119, doi:10.1029/2010JD014574, 2011.

Holz, R. E., Ackerman, S. A., Nagle, F. W., Frey, R., Dutcher, S., Kuehn, R. E., Vaughan, M. A., and Baum, B.: Global Moderate Resolution Imaging Spectroradiometer (MODIS) cloud detection and height evaluation using CALIOP, J. Geophys. Res., 113, D00A19, doi:10.1029/2008JD009837, 2008.

$\mathrm{Hu}$, Y., Vaughan, M. A., Winker, D. M., Liu, Z., Noel, V., Bissonnette, L. R., Roy, G., McGill, M., and Trepte, C. R.: A simple multiple scattering-depolarization relation of water clouds and its potential applications, Proceedings of 23nd International Laser Radar Conference, Nara, Japan, 19-22, 2006.

$\mathrm{Hu}$, Y., Winker, D., Vaughan, M., Lin, B., Omar, A., Trepte, C., Flittner, D., Yang, P., Sun, W., Liu, Z., Wang, Z., Young, S., Stamnes, K., Huang, J., Kuehn, R., Baum, B., and Holz, R.: CALIPSO/CALIOP Cloud Phase Discrimination Algorithm, J. Atmos. Oceanic Technol., 26, 2293-2309, doi:10.1175/2009JTECHA1280.1, 2009.

Josset, D., Pelon, J., Garnier, A., Hu, Y.-X., Vaughan, M., Zhai, P., Kuehn, R., and Lucker, P.: Cirrus optical depth and lidar ratio retrieval from combined CALIPSO-CloudSat observations using ocean surface echo, J. Geophys. Res., 117, D05207, doi:10.1029/2011JD016959, 2012.

Leahy, L. V., Wood, R., Charlson, R. J., Hostetler, C. A., Rogers, R. R., Vaughan, M. A., and Winker, D. M.: On the nature and extent of optically thin marine low clouds, J. Geophys. Res., 117, D22201, doi:10.1029/2012JD017929, 2012.

Lewis, J. R., Campbell, J. R., and Welton, E. J.: Overview and analysis of the MPLNET Version 3 cloud detection algorithm, J. Atmos. Oceanic Technol., in preparation, 2015.

Liou, K.-N.: The influence of cirrus on weather and climate processes: A global perspective, Mon. Weather Rev., 114, 11671199, 1986.

Liu, Z., Vaughan, M., Winker, D., Kittaka, C., Getzewich, B., Kuehn, R., Omar, A., Powell, K., Trepte, C., and Hostetler, C.: The CALIPSO lidar cloud and aerosol discrimination: version 2 algorithm and initial assessment of performance, J. Atmos. Oceanic Technol., 26, 1198-1213, 2009.

Lynch, D. K.: Cirrus: history and definition, in: Cirrus, edited by: Lynch, D. K., Sassen, K., O'C. Starr, D., and Stephens, G., Oxford University Press, New York, 480 pp., 2002.

Nazaryan, H., McCormick, M. P., and Menzel, W. P.: Global characterization of cirrus clouds using CALIPSO data, J. Geophys. Res., 113, D16211, doi:10.1029/2007JD009481, 2008.

O’Connor, E. J., Illingworth, A. J., and Hogan, R. J.: A technique for autocalibration of cloud lidar, J. Atmos. Oceanic Technol., 21, 777-786, 2004.

Pruppacher, H. R. and Klett, J. D.: Microphysics of Clouds and Precipitation, 2nd Edn., Kluwer, 954 pp., 1997.

Sassen, K.: Backscattering cross sections for hydrometeors: measurements at $6328 \mathrm{~A}^{\circ}$, Appl. Opt., 17, 804-806, 1978.

Sassen, K.: The polarization lidar technique for cloud research: a review and current assessment, Bull. Am. Meteorol. Soc., 72, 1848-1866, 1991.
Sassen, K.: Cirrus clouds: A modern perspective, in: Cirrus, Lynch, D., Sassen, K., O'C. Starr, D., and Stephens, G., Oxford University Press, New York, 480 pp., 2002.

Sassen, K. and Campbell, J. R.: A midlatitude cirrus cloud climatology from the Facility for Atmospheric Remote Sensing Part I: macrophysical and synoptic properties, J. Atmos. Sci., 58, 481496, 2001.

Sassen, K. and Cho, B. S.: Subvisual-thin cirrus lidar dataset for satellite verification and climatological research, J. Appl. Meteor., 31, 1275-1285, 1992.

Sassen, K. and Comstock, J. M.: A midlatitude cirrus cloud climatology from the facility for atmospheric remote sensing, Part III: radiative properties, J. Atmos. Sci., 58, 2113-2127, 2001.

Seifert, P., Ansmann, A., Groß, S., Freudenthaler, V., Heinold, B., Hiebsch, A., Mattis, I., Schmidt, J., Schnell, F., Tesche, M., Wandinger, U., and Wiegner, M.: Ice formation in ashinfluenced clouds after the eruption of the Eyjafjallajökull volcano in April 2010, J. Geophys. Res., 116, D00U04, doi:10.1029/2011JD015702, 2011.

Stephens, G. L., Tsay, S., Stackhouse Jr., P. W., and Flatau, P. J.: The relevance of the microphysical and radiative properties of cirrus clouds to climate and climate feedback, J. Atmos. Sci., 47, 1742-1753, 1990.

Stephens, G. L., Vane, D. G., Boain, R. J., Mace, G. G., Sassen, K., Wang, Z., Illingsworth, A. J., O'Connor, E. J., Rossow, W. B., Durden, S. L., Miller, S. D., Austin, R. T., Benedetti, A., and Mitrescu, C.: The Cloudsat mission and the A-Train: a new dimension of space-based observations of clouds and precipitation, Bull. Am. Meteorol. Soc., 83, 1771-1790, doi:10.1175/BAMS83-12-1771, 2002.

Sun, Z. and Shine, K. P.: Studies of the radiative properties of ice and mixed-phase clouds, Q. J. R. Meteorol. Soc., 120, 111-137, 1994.

Thorsen, T. J., Fu, Q., and Comstock, J.: Comparison of the CALIPSO satellite and ground-based observations of cirrus clouds at the ARM TWP sites, J. Geophys. Res., 116, D21203, doi:10.1029/2011JD015970, 2011.

Vaughan, M. A., Powell, K. A., Kuehn, R. E., Young, S. A., Winker, D. M., Hostetler, C. A., Hunt, W. H., Liu, Z., McGill, M. J., and Getzewich, B. J.: Fully automated detection of cloud and aerosol layers in the CALIPSO lidar measurements, J. Atmos. Oceanic Technol., 26, 2034-2050, 2009.

Virts, K. S. and Wallace, J. M.: Annual, interannual, and intraseasonal variability of tropical tropopause transition layer cirrus, J. Atmos. Sci., 67, 3097-3112, 2010.

Virts, K. S., Wallace, J. M., Fu, Q., and Ackerman, T. P.: Tropical tropopause transition layer cirrus as represented by CALIPSO lidar observations, J. Atmos. Sci., 67, 3113-3129, 2010.

Wang, Z., Sassen, K., Whiteman, D. N., and Demoz, B. B.: Studying altocumulus with ice virga using ground-based active and passive remote sensors, J. Appl. Meteorol., 43, 449-460, 2004.

Winker, D. M., Pelon, J., Coakley Jr., J. A., Ackerman, S. A., Charlson, R. J., Colarco, P. R., Flamant, P., Fu, Q., Hoff, R., Kittaka, C., Kubar, T. L., LeTreut, H., McCormick, M. P., Megie, G., Poole, L., Powell, K., Trepte, C., Vaughan, M. A., and Wielicki, B. A.: the CALIPSO mission: A global 3D view of aerosols and clouds, Bull. Am. Meteorol. Soc., 91, 1211-1229, 2010.

World Meteorological Organization: International Cloud Atlas, vol. I, Manual on the Observation of Clouds and other Mete- 
ors, World Meteorological Organization, Geneva, 1975, updated 1995.

Yorks, J. E., Hlavka, D. L., Hart, W. D., and McGill, M. J.: Statistics of cloud optical properties from airborne lidar measurements, $\mathrm{J}$. Atmos. Oceanic Technol., 28, 869-883, 2011.

Young, S. A. and Vaughan, M. A.: The retrieval of profiles of particulate extinction from Cloud-Aerosol Lidar Infrared Pathfinder Satellite Observations (CALIPSO) data: algorithm description, J. Atmos. Ocean. Technol., 26, 1105-1119, 2009.
Young, S. A., Vaughan, M. A., Kuehn, R. E., and Winker, D. M.: The retrieval of profiles of particulate extinction from Cloud-Aerosol Lidar Infrared Pathfinder Satellite Observations (CALIPSO) data: uncertainty and error sensitivity analyses, J. Atmos. Oceanic Technol., 30, 395-428, 2013.

Zhang, D., Wang, Z., and Liu, D.: A global view of midlevel liquidlayer topped stratiform cloud distribution and phase partition from CALIPSO and CloudSat measurements, J. Geophys. Res., 115, D00H13, doi:10.1029/2009JD012143, 2010. 